\title{
Research on the Coordinative Development of Regional Higher Education and Economy
}

\author{
Yingjun Hong \\ Wenzhou University, Wenzhou 325035, China \\ Tel: $13587630661 \quad$ E-mail: hyj@wzu.edu.cn
}

Received: December 7, 2011 Accepted: December 12, 2011 Published: March 1, 2012

doi:10.5539/hes.v2n1p51

URL: http://dx.doi.org/10.5539/hes.v2n1p51

\begin{abstract}
In the current society, economic development in any region has to rely on higher education. Conversely, higher education cannot do without regional economic development in order to achieve greater progress in scale and level. Starting with the function of higher education in Wenzhou, this paper analyzes the reality and problems in Wenzhou's higher education and comes up with countermeasures for its further development in order to constantly promote the coordinative development of Wenzhou's higher education and regional economy.
\end{abstract}

Keywords: Regional higher education, Wenzhou, Development

\section{Introduction}

As for some scholars, higher education exerts its propelling functions on regional economy from three aspects: first is to be actively adapted to the need for the development of advantageous resources and industries in the local region; second is to be adjusted to the trend of local economic conglomeration to promote the expansion of local economy; third is to be adapted to integrative global economy to push local economy to the international market (Shaofen $\mathrm{Wu}$, 2001). Based on the above, the integration function of higher education in regional development should be fully exerted to promote the coordinative development of higher education and some internal factors belonging to the region such as economy, politics, culture, environment as well as population.

Modernization has to be based on modern education, especially higher education, without which no high-quality talents can be cultivated and no modernization can be achieved eventually (Xiaoping Deng,1994). It is of particular significance for Wenzhou's urbanization to explore how Wenzhou's higher education should serve the development of social economy.

\section{Functions and Characteristics of Wenzhou's Higher Education}

Currently, higher education is exerting the following functions in Wenzhou's economic development and social progress.

\subsection{Offering High-quality Talents}

In Zhejiang, one of the most vigorous provinces in economic development, Wenzhou is among the top with its rapid and vigorous economic development (Fusheng, C., 2009). In spite of certain development in its higher education in the recent years, Wenzhou is still held back by insufficient higher education resources and human resources as well as unreasonable structure. With talents being the top resources, an increasing number of high-quality management talents and rare technical professionals in foreign trade, advanced administrative management and international finance should be cultivated along with the economic and social development and greater competition pressure. It will offer effective talent support for the establishment of top talent bank in Wenzhou to develop its higher education and cultivate urgently-needed high-quality talents.

\subsection{Perfecting Wenzhou's Urban Function to Promote the Formation of Life-long Education System and a Learning-oriented City}

Now, a majority of universities are located in the northern part of Zhejiang province. As one of the first opened coastal cities in China, a focus city in Zhejiang as well as a central city in North Zhejiang and East Fujian, Wenzhou has underdeveloped higher education which isn't in conformity with its urban image and regional orientation. By developing its higher education and constructing a university city, its surrounding areas can be affected as well, helping to form other learning-oriented communities, improving citizens' quality and cultural taste of the whole city, shaping its city image as well as improving and fully exerting Wenzhou's function as a central city. 


\subsection{Satisfying People's Need for Higher Education and Creating New Economic Growth Point}

With developed private economy and considerable folk capital in Wenzhou, people have increasing ability and passion for education input. Ever since the popularization of nine-year compulsory education in Wenzhou, an increasing number of high school graduates are eager for higher education. However, its laggard higher education cannot satisfy people's strong demands for high-quality higher education (Fusheng, C., 2009). As is revealed in foreign countries' experiences, higher education is attached great importance to in many countries since its huge industrial chain could exert its strong pull on economic development, especially in developed countries or areas(Wanbing, S., 2004). The construction of a university city can help to exert the combined advantages of different universities, to provide intellectual support for regional economy, to offer more local employment opportunities, to promote the development of real estate as well as to adapt students earlier to the market environment.

\subsection{Strengthening the Integration of Production, Teaching and Research to Provide a Platform for Technological Innovation}

Seen from the world, "Wisconsin Idea" clearly lists social service as one of the main functions for universities and colleges, hence starting the trend of regional higher education directly serving regional economy and social development (Tongwen, X., 2004). Compared with developed nations, China's regional higher education tends to be laggard, so does its social service system. The industry section of Wenzhou has been developed based on labor-intensive manufacturing industries, producing low-level products with low added value and poor profit, which makes it hard to survive the competition home and abroad. To develop higher education in Wenzhou can encourage technical staff in universities and research institutes to be involved in the integration of production, teaching and research, hence beneficial for technical innovation and the adjustment of local industrial structure.

\section{The Reality of Wenzhou's Higher Education}

By 2011, there have been 6 general colleges, including Wenzhou Medical College, Wenzhou University, Wenzhou Vocational and Technical College, Zhejiang Industry and Trade Vocational College, Zhejiang Oriental Vocational and Technical College and Wenzhou Vocational College of Science and Technology as well as one college for adults and 38 long-range education stations. The development of higher education at different levels and of different types has provided Wenzhou with a large array of skilled laborers and various professionals, propelling economic and social development and hence exerting a significant role in the all-round development of the city of Wenzhou.

\subsection{Insufficient High-level Talents and Structural Absence of Human Resources}

Due to its small number of colleges, Wenzhou has poor strength in higher education, hence lacking in impact on discipline construction, specialty construction and research contribution. Whether the hierarchical structure and specialty structure for talent cultivation is reasonable or not will have a direct influence on the supply of talents for regional economic development as well as the employment of graduates. According to relevant plan, Wenzhou is to establish an advanced manufacturing base, to follow the path of new-type industrialization, to develop high-tech industries based on optical, mechanical and electronic integration, electronic information, biological medicine and new materials, having an urgent need for engineering majors (Wenzhou Municipal People's Government, 2011). Looking around the colleges in Wenzhou, relevant specialties are insufficient, so are the talents called for by new industries.

\subsection{Onefold School-Running Pattern and Lack of Vitality}

Except Wenzhou Medical College which is a provincial college, all colleges in Wenzhou are local ones. Owned by the state, these universities have onefold investment and operation system for higher education, hence failing to exert such an economic power's role in this aspect and leading to a lack of vitality in higher education. Actually, in specialty setting and disciplinary layout, colleges pay more attention to the development layout of their disciplines than to social demands from an economic perspective, which has led to the similarities in the setting of disciplines and specialties as well as the level of talents in different colleges and therefore has been away from the actual demands of economic and social development.

\subsection{Imperfect Operation and System of the Integration of Production, Teaching and Research}

Due to poor science and technology capacity as well as the small number of colleges and talents especially advanced talents, technological innovation in Wenzhou's enterprises has been severely held back, hindering the sound development of its economy. It is revealed in a survey among 225 enterprises in Wenzhou that $72.6 \%$ of them take it as a channel for technological innovation to strengthen their independent development ability; $33 \%$ of them have regular joint research and development activities with research institutes; $37.3 \%$ of them occasionally do that while $30 \%$ rarely or never do that mainly due to the lack of talents, facilities and capital for technological transformation 
as well as immature technologies owned by colleges and research institutes(Huanchun,Y., 2006).

\section{Countermeasures for the Development of Wenzhou's Higher Education}

According to the analysis from the perspectives of population and GDP conducted by Hongbin Zhao(2007) and others, some developed cities have a small number of specialty students and undergraduates as well as the number of students per GDP unit (hundred million yuan)(such as in Taizhou, Wenzhou, Foshan and so on), failing to exert the desirable effect of colleges on the development of local economy. Only by seizing opportunities to greatly develop higher education will economy be promoted effectively.

\subsection{Clarifying Opportunities for the Development of Wenzhou's Higher Education}

With the transformation in economic structure and economic growth mode, guided by the scientific concept of development, previous extensive economy mainly based on resources and environmental consumption is to be transformed into intensive economy with intensive knowledge and technology and therefore economic development will rely more on technological innovation and high-quality talents. Meanwhile, human social science is called for urgently to accomplish harmonious society and people's all-round development. All these will offer an immense space for colleges to exert their advantages in talents and intelligence, to expand their social service function and to make greater contributions for the development of national and local economy and society. In addition, Zhejiang has established the construction of a great power in education as its strategy in which three centers of higher education will be developed including Hangzhou, Ningbo and Wenzhou (Fusheng,C.,2009), which provides a historic opportunity for Wenzhou's higher education.

\subsection{Adjusting the Structure of Higher Education and Changing Its Growth Mode}

In order to meet the demands for social development, Wenzhou's higher education needs to be adjusted in an all-round way in its specialty structure, hierarchical structure, regional structure and form structure. In the aspect of specialty structure, Wenzhou's actual demands by economic structure should be based on, current industrial structure adjustment should be taken as the mainline and social demands should take the guidance role to facilitate the cultivation of talents for the manufacturing and service industries, to establish specialties relevant to interdisciplinary branches and newly-established technologies to satisfy the needs of employers. In regional structure, the university city should be centered to radiate its influence to other areas to improve the demands for talent cultivation and to reasonably arrange educational resources (Qinghe,L.,2010), Y.. In hierarchical structure, actual regional demands should be relied on and local resources should be made full use of to have multi-level education to satisfy the demands for talents at different levels. In form structure, a higher education network structure with coordinative development as well as complementary advantages should be established.

\subsection{Reforming School-Running System and Accomplishing Diversified Patterns}

With the dominant role of state education, folk capital should be made use of to develop independent colleges. A large sum of idle capital is waiting for new investment channels, for which running independent colleges serves as a new direction. In 2001, Wenzhou Government issued The Announcement of Interim Measures on Wenzhou University's Collecting Capital for Running School (2007) to fully exert the activity and creativity of different sections and properly gather strengths for school running from different parts of our society. It is also clearly pointed out in On Regulating and Strengthening the Supervision on the Establishment of Independent Colleges by General Universities (The Ministry of Education, 2004) that independent colleges should be intended for the objective demands of local economic and social development to serve them in an effective way.

\subsection{Strengthening the Integration of Production, Teaching and Research to Offer a Supportive Platform for} Technological Innovation

Colleges' significant role in independent innovation should be fully exerted by encouraging enterprises and colleges to establish institutions for technological development in different forms with different systems to provide more mature and profitable achievements for enterprises. Meanwhile, science and technology staff at college can go into enterprises to develop the integration of production, teaching and research in order to facilitate the transfer of scientific achievements. For instance, a leading group for colleges' service for local development has been established in Wenzhou University, which has done a lot to establish and conduct an action plan to serve Wenzhou, to promote a project of encouraging talents with various ideas and specialties as well as a project for the alliance of production, teaching and research and to improve the quality and contribution rate of college's service for the local society in accordance with the research and prediction on the development of Wenzhou's economy and society (Xiuhui,P.,2006). 
4.5 Strengthening the Cultivation and Introduction of High-quality Talents and Improving School-running Quality and Level

In the recent years, Wenzhou Government and relevant departments have made greater efforts to attract talents. However, with the increasingly fierce competition for talents, it will be more difficult and consuming to attract the limited number of talents. At present, a majority of talents here are attracted form the central and western part of China, which is a violation against the national policy to develop the western area, hence holding back the coordinative development of the whole nation. It is shown in practice that developing Wenzhou's higher education should be taken as a priority based on Wenzhou's reality in order to cultivate high-quality talents for local economy. With the expansion of higher education scale, we are expected to start out from the reality to establish a plan for staff construction, to issue preferential policies and to cultivate or attract high-level talents so as to improve staff structure and improve their capacity.

\section{References}

Fusheng, C. (2009). Advance three transformation, raise the level of education, \& create a new situation of scientific development of the school. Journal of Wenzhou University (Social Sciences). (3). 1-4. http://dx.doi.org/10.3875/j.issn.1674-3555.2009.03.001

Hongbin, Z., \& Niancai, L. (2007). A Research on Chinese Universities' Regional Distribution: From the Perspective of Population and GDP. Higher Education Research. (1). P47.

Huanchun, Y. (2007). Survey and Analysis of Technological Innovation Competence and output of Enterpr ises in Wenzhou. Science of Science and Management of S. \& T. (9). 47-49.

Qinghe, L., \& Huajie, Y. (2010). An Analysis on the Economic Effects of Developing University Towns. Journal of Shenzhen University (Humanities \& Social Sciences). (6).73-76

Shaofen, W., \& Zefang, D. (2001). Distinguishing the Definition of Regional Concentration of Higher Education. Education and Economy. (2). 9-11

The Ministry of Education. (2004). On Regulating and Strengthening the Supervision on the Establishment of Independent Colleges by General Universities. [Online] Available: http://www.edu.cn/20040212/3098888.shtml (February12, 2004)

Tongwen, X. (2004). The mission of Regional Universities. Beijing: Education Science Press. 23-26

Wanbing, S. (2004). Economics of Higher Education. Beijing: Science Press, 274

Wenzhou Municipal People's Government. (2011). The twelfth five year scheme of Wenhzou - the Development of strategic emerging industries. [Online] Available: http://www.wenzhou.gov.cn/art /2011/11/14/art_4244_192240.html (November14, 2011)

Wenzhou Municipal People's Government. (2007). The Announcement of Interim Measures on Wenzhou University's Collecting Capital for Running School. [Online] Available: http://www.wenzhou.gov.cn/art/2007/7/23/art_4459_68.html (July 23, 2007)

Xiaoping, D. (1994). Deng Xiaoping anthology (3rd volumes). Beijing: People's Press, 35

Xiuhui, P. (2006). Open the colleges and universities door and serve the local better-Interview Chen Fusheng,the president of Wenzhou University. [Online] Available: http://www.wzrb.com.cn/system /2006/09/26/100188789.shtml (September 26, 2006) 